\title{
Muerte digna: ¿Algo está cambiando?
}

\author{
Dignified death: Something is changing?
}

Rosa Angelina Pace

\section{Resumen}

La autora de este artículo, a raíz de un fallo reciente muy resonante en la Argentina sobre el derecho a la muerte digna, reflexiona acerca de los cambios en nuestra sociedad contemporánea, las dificultades que esto suscitó respecto de la aceptación de la limitación terapéutica en casos terminales e irreversibles, y la necesidad de reflexionar y discutir esta temática como sociedad.

Palabras clave: muerte digna, autonomía, directivas anticipadas, bioética.

Pace R. Muerte digna: ¿Algo está cambiando?. Evid Act Pract Ambul. 2015 (2). Abr-Jun. 33

El fallo reciente de la Corte Suprema de Justicia respecto del caso Marcelo Diez, el hombre por quien sus hermanas lucharon durante años para que se le concediera el derecho a tener una muerte digna ${ }^{1}$, nos viene a confirmar las múltiples fuerzas que se ejercen sobre la medicina. Entre estas fuerzas, las legales no son las únicas ya que son diferentes los actores que juegan en este terreno del ejercicio de nuestra profesión. Las industrias de medicamentos, los fabricantes de todo tipo de tecnología, la sociedad misma y sus deseos de cantidad y calidad de vida han llevado a que la salud se transforme en un bien de consumo. Todo eso hizo que la medicina se transformara en una fuerza económica más, lo que en los últimos años del siglo XX ha tenido un crecimiento exponencial.

Pero en este devenir, un poco por ingenuidad de quienes practicamos la medicina, hemos perdido el rumbo de para qué hacemos lo que hacemos. ¿Tiene sentido mantener en estado vegetativo o en estado de mínima conciencia a una persona durante 20 años? ¿Tenemos obligación de sostener una alimentación y una hidratación artificial sin un objetivo de recuperación alguno? ¿Tiene sentido obtener resultados marginales, tanto con grandes costos socioeconómicos, como de esperanza de los pacientes y de su entorno? ¿Cuáles deberían ser los Fines de la medicina? Estamos llenos de medios, la mayoría tecnológicos, tanto de diagnóstico como de tratamiento, pero hemos perdido el norte en cuanto a los fines.

¿Para qué hacemos lo que hacemos? ¿Adónde apuntamos nuestros objetivos? ¿Dónde haremos foco?

Esto y mucho más se preguntaron un grupo de pensadores de 14 países del mundo liderado por el Centro Hasting (Hasting Center) ${ }^{2}$, que trabajaron durante varios años y produjeron un documento con sus conclusiones, que puede leerse gratuitamente en forma completa en: http://comitebioetica.cat/wp-content/uploads/2012/10/fins_medicina.pdf

Este consenso comienza comunicando una definición de saludenfermedad menos ambiciosa que la que la Organización Mundial de la Salud (OMS) instaló hace varias décadas, y consideramos que contribuyó a oscurecer los fines de nuestra labor médica. En este contexto, proponen que:

“...la salud se caracteriza por la ausencia de males de consideración y, por tanto, por la capacidad de una persona para perseguir sus metas vitales y desenvolverse adecuadamente en contextos sociales y laborales habituales. Con esta definición queremos subrayar el énfasis tradicional en la integridad y el buen funcionamiento del cuerpo, la ausencia de disfunciones y la consiguiente capacidad de actuar en el mundo..."

A continuación procuran delinear ciertas directrices que deberían guiar la práctica de la medicina²:
1. La prevención de enfermedades y lesiones, y la promoción y la conservación de la salud.

2. El alivio del dolor y el sufrimiento causados por diferentes dolencias.

3. La atención y la curación de los enfermos, y los cuidados a quienes padecen males incurables.

4. La evitación de la muerte prematura y la búsqueda de una muerte tranquila.

5. El respeto de las opciones y la dignidad de las personas.

El documento es largo y merece más de una lectura atenta. No es el objetivo de esta editorial resumirlo sino, sino solamente mencionarlo para iluminar el caso que nos movilizó durante años. Como es fácil notar, la situación a la que estuvo sometido este paciente aún después de que en nuestro país se sancionara la ley 26.529 de derechos de los pacientes y su modificatoria, la 26.742 es, a todas luces, aberrante. $Y$ su caso estuvo a merced de diversas opiniones, algunas fundamentalistas. Vale destacar que tres comités de bioética ya se habían expedido a favor de "permitirle" morir.

¿Es ésta una medicina deseable? ¿Qué valores obligan a mantener en este estado a un cuerpo sin capacidad de entender su situación ni de mantener comunicación con su entorno?

A esta altura de nuestra evolución como sociedad, hemos podido consensuar las leyes antes citadas que en cierto modo garantizan nuestro derecho a decidir. Hemos llegado a aceptar ciertas herramientas como las Directivas Anticipadas, que tienen cierta utilidad a la hora de conocer nuestros deseos y guiar a nuestras familias y médicos cuando ya hemos perdido la conciencia. Consideramos que, con ciertas limitaciones, como la de introducir la figura de un escribano o un juez de primera instancia, las directivas anticipadas son un elemento útil, tanto para ser ofrecida a los pacientes como para ser usadas en nuestras propias vidas.

Es hora de que reflexionemos seriamente acerca de nuestros fines y nuestros objetivos, que promovamos la autonomía de nuestros pacientes, que los invitemos a expresarse en cuanto a sus preferencias, y que podamos desarrollar los argumentos para hacer una medicina centrada en los fines de sus destinatarios y no puramente funcional a los intereses de otros.

La discusión acerca de los fines no está acabada, es un tema siempre abierto, pero el compromiso de la reflexión al respecto es imperativo. Es por el bien de nuestros pacientes, por el bien de quienes trabajamos en el área de la salud -también alguna vez nos toca ser pacientes- por racionalidad económica, y por el bien de nuestra sociedad.

Recibido el 20/07/15 y aceptado el 28/07/2015.

\section{Referencias}

1. La Nación. La historia de Marcelo Diez, el hombre que pudo acceder a una muerte digna.

http://www.lanacion.com.ar/1808451-la-historia-de-marcelo-diez-el-hombre-que-podra-acceder-a-una-muerte-digna, accedido el 24/07/2015.

2. Fundación Víctor Grífols. Los fines de la medicina, Fundació Víctor Grífols i Lucas, 2005, Barcelona. Disponible en URL: http://comitebioetica.cat/wpcontent/uploads/2012/10/fins_medicina.pdf

* Comité de Ética y Servicio de Cirugía General del Hospital Italiano de Buenos Aires. rosina.pace@ hiba.org.ar 